\title{
Analisis Pendapatan Usaha Peternakan Ayam Buras Petelur dengan Menerapkan Teknologi Pakan Limbah Ternak Sapi (Studi Kasus di Kelompok Tani Ternak Sato Nadi, Kecamatan Tembuku, Kabupaten Bangli)
}

\author{
SRIYANTO, I GEDE SETIAWAN ADI PUTRA, I PUTU DHARMA \\ Program Studi Agribisnis, Program Non Reguler, Fakultas Pertanian \\ Universitas Udayana. Jl. PB Sudirman 80232 Denpasar \\ Email: jmasyan@yahoo.com \\ setiawanadiputra@roketmail.com
}

\begin{abstract}
Analysis of Operating Revenues ofLaying Domestic Poultry by Applying the Waste Cattle Feed Technology (A Case Study in Farmers Group of Sato Nadi, Sub-District of Tembuku, Bangli Regency)
\end{abstract}

Feed is the major determinant in the success of farming and as a means of support for the improvement of productivity of poultry. During this time the availability of livestock feed has been supplied from outside the island of Bali and is relatively expensive. This is an opportunity for farmers in the village of Jehem to be able to meet their needs for cheaper poultry feed mainly for the domestic poultry made fromcattle waste. The purpose of this study was to determine the level of income received by farmers and the constraints faced in domestic poultry farm. This research was conducted in the farmer groups of Sato Nadi, Sub-District of Tembuku, Bangli Regency.The total sample was as many as 22 farmers involved in the business of laying domestic poultry. The analytical method used was the method of quantitative and qualitative descriptiveanalysis, analysis of farming, and the $\mathrm{R} / \mathrm{C}$ ratio. The results showed that the income received by farmers in the domestic poultry farmer group of Sato Nadi, Jehem Village, Sub-District of Tembuku, Bangli Regency was $\mathrm{Rp} 1,901,847.80$ / 100 chickens in the group of conventional feed, and Rp 2,640,111 , 78/100 chickensfor the group that applied Cattle waste feed, and R / C Ratio obtained respectively of 1.11 and 1.15 . The twofarmer groupsof domestic poultry farm are feasible to be developed and profitable. The constraint faced by the farmers was factor of the increase in feed prices that are not accompanied by the rising of production prices cause smaller profits for the farmers. Suggestions that can be given in this research are the governmentshould reduce variable costs through the use of feed of cattle manure flour and good profits can be obtained if the farmers willing to produce the feed by their own and do not buy the finished feed.

Keywords: poultry, cattle, farms 


\section{Pendahuluan}

\subsection{Latar belakang}

Pembangunan peternakan pada era globalisasi bertujuan untuk mewujudkan masyarakat yang sehat, produktif, dan kreatif melalui peternakan yang tangguh berbasis sumberdaya lokal. Ayam buras merupakan ayam asli yang sudah beradaptasi dengan lingkungan tropis Indonesia. Sumbangan daging ayam buras terhadap produksi daging nasional sebesar $10 \%$ atau sekitar 297,65 ribu ton (Ditjen Peternakan dan Kesehatan Hewan, 2015).

Ayam Bali termasuk salah satu ayam buras dan sering juga disebut ayam kampung (Rasyaf, 1995). Populasi ayam buras di Bali mencapai 4.644 .548 ekor untuk tahun 2010, meningkat $1,46 \%$ jika dibanding tahun 2009 sebanyak 4.577 .895 ekor. Tahun 2011 sampai 2014 terjadi penurunan populasi ayam buras bali menjadi 4.396.174 ekor (2011), dan tahun 2014 terus menurun menjadi 4.111 .438 ekor (Disnak dan Keswan Provinsi Bali, 2014). Turunnya populasi disesbabkan wabah penyakit flu burung serta semakin mahalnya biaya pakan ayam buras, sehingga tidak mampu ditutupi oleh produktivitas yang dihasilkannya.Ayam Buras Bali memiliki potensi sebagai penghasil telur (Suwindra, 1994), namun karena dalam pemeliharaan tidak dilakukan upaya seleksi secara terarah, sehingga ayam Bali ini sebagaimana ayam lokal lain, pencapaian produktivitas rata-rata cenderung rendah (Rasyaf, 1992).

Total produksi telur di Bali sebesar 39.562,85 ton, sekitar 7,51\% (2.972,85 ton) diantaranya adalah produksi telur ayam buras(Disnak dan Keswan Provinsi Bali, 2013). Salah satu kendala dalam pengembangan budidaya ayam adalah pakan. Pakan merupakan komponen biaya tertinggi dalam usaha peternakan unggas termasuk ternak ayam buras, dan adanya keterbatasan beberapa bahan pakan, sehingga sebagian masih harus diimpor (Sinurat, 1999). Hasil penelitian BPTP-Bali tahun 2013, menunjukkan bahwa kotoran sapi yang telah diolah melalui proses fermentasi, dapat dimanfaatkan dalam ransum ayam buras hingga 15\%, tanpa berpengaruh secara nyata terhadap produktivitas telur, meskipun kandungan energi ransum lebih rendah (Guntoro, dkk., 2014).

\subsection{Tujuan}

Tujuan dari penelitian ini adalah :

1. Mengetahui perbedaan tingkat pendapatan antara usaha peternakan ayam buras petelur dengan menerapkan teknologi pakan limbah ternak sapi, dibandingkan dengan usaha ternak ayam buras petelur secara konvensional.

2. Mengetahui kendala apa saja yang dihadapi dalam usaha peternakan ayam buras petelur di kelompok tani ternak Sato Nadi, Kabupaten Bangli. 


\section{Metode Penelitian}

\subsection{Lokasi dan Waktu Penelitian}

Penelitian ini dilakukan di Kelompok Tani Sato Nadi, Kecamatan Tembuku, Kabupaten Bangli. Penelitian ini dilakukan pada 1 (satu) siklus produksiyaitu bulan Mei sampai bulan Oktober 2014.Pemilihan lokasi penelitian dilakukan secara purposive sampling yaitu penetapan lokasi secara sengaja dengan suatu pertimbangan tertentu.

\subsection{Penentuan Populasi, Sampel dan Responden}

Populasi dalam penelitian ini adalah seluruh petani/anggota Kelompok Tani Sato Nadi yang menerapkan teknologi pakan limbah ternak sapi dan secara konvensional, yaitu sebanyak 22 orang. Anggota kelompok taniyang telah menerapkan teknologi pakan limbah ternak sapi untuk pakan ayam buras petelur sebanyak 13 orang dan 9 orang lagi dengan menggunakan pakan konvensional.Sampel diambil dari populasi dengan menggunakan metode sensus yaitu keseluruhan petani pengguna kedua teknologi pakan ternak langsung digunakan sebagai responden.

\subsection{Sumber dan Jenis Data}

Data yang dikumpulkan pada penelitian ini bersumber dari data primer dan data sekunder. Data primer diperoleh dari hasil wawancara dengan petani yang melakukan usaha peternakan ayam buras petelur baik yang menerapkan teknologi pakan limbah sapi maupun menggunakan pakan secara konvensional. Data sekunder diperoleh dari berbagai sumber kepustakaan.

\subsection{Teknik Pengumpulan Data}

Teknik pengumpulan data yang digunakan dalam penelitian ini adalah metode deskriptif. Pengumpulan data dalam penelitian ini bersumber dari;(a) wawancara langsung kepada petani responden,(b) studi pustaka, dan (c) observasikeragaan teknologi pakan ternak yang diterapkan di lokasi penelitian.

\subsection{Analisis Data}

Data penelitian ini dianalisis dengan metode analisis kuantitatif dan analisis deskriptif kualitatif. Analisis data usaha peternakan ayam buras petelur, menggunakan perhitungan usahatani, R/C Ratio. Data dianalisis melalui penafsiran data yang ada, dengan tujuan untuk mendeskripsikan secara rinci suatu fenomena sosial tertentu dengan penafsiran disertai interprestasi rasional terhadap faktor-faktor yang ada dilapangan. 


\section{Hasil dan Pembahasan \\ 3.1 Gambaran Umum}

Kecamatan Tembuku merupakan kecamatan yang memiliki luas wilayah paling kecil $\left(48,32 \mathrm{~km}^{2}\right)$ dari 4 kecamatan yang ada di Kabupaten Bangli dengan batas-batas, sebelah utara Kecamatan Kintamani, sebelah timur Kecamatan Rendang Kabupaten Karangasem, sebelah barat Kecamatan Bangli,serta sebelah selatan Kecamatan BanjarangkanKabupaten Klungkung. Menurut penggunaannya luas wilayah Kecamatan Tembuku terdiri 16,72\% lahan sawah, 27,50\% lahan tegalan, 41,12\% lahan perkebunan, 4,42\% lahan pekarangan, 0,33\% kuburan dan lainnya 9,91\%.Kecamatan Tembuku terdiri dari 6 Desa, yaitu Desa Jehem, Desa Tembuku, Desa Undisan, Desa Yangapi, Desa Peninjoan, dan Desa Bangbang (BPS. Kab. Bangli, 2015)

Kelompok Tani Ternak Sato Nadiberdiri pada tanggal 12 Nopember 2013 di Desa Jehem Kecamatan Tembuku, Kabupaten Bangli.Desa Jehem berpenduduk 7.660 orang yang sebagian besar berusia produktif sebanyak 4.761 orang $(62,15 \%)$. Mata pencaharian penduduknya sebagai petani sawah $(28,79 \%)$, petani kebun $(44,75 \%)$, dan sebanyak $(14,61 \%)$ sebagai pengrajin, selebihnya $(11,85 \%)$ bekerja sebagai peternak, buruh tani, buruh bangunan, karyawan, PNS, TNI, dan POLRI. Desa Jehem dibatasi beberapa desa, sebelah utara Desa Landih, sebelah timur Desa Tembuku, sebelah selatan Desa Bungbungan, dansebelah barat Desa Cempaga(Daftar Isian Profil Desa Jehem, 2014).

\subsection{Analisis Usaha Peternakan Ayam Buras Petelur}

\subsubsection{Produksi dan penerimaan usha peternakan ayam buras petelur}

Penerimaan usaha ternak ayam buras petelur yang diusahakan peternak di Kelompok Tani Ternak Sato Nadi Desa Tembuku tergantung pada banyaknya jumlah telur yang dihasilkan. Jumlah telur yang dihasilkan peternak biasanya sebagian besar dijual dan sebagian kecil dikonsumsi untuk kebutuhan rumah tangga.

\section{Tabel 1.}

Rata-rata Jumlah Produksi dan Penerimaan Usaha Peternakan Ayam Buras Petelur Sebanyak 100 Ekor dengan Teknologi Pakan Limbah Sapi dan Menggunakan Pakan Konvensional Selama Satu Siklus Produksi (Mei-Oktober 2014)

\begin{tabular}{cccccccccc}
\hline & Produksi & \multicolumn{4}{c}{ Pakan Konvesional } & \multicolumn{3}{c}{ Pakan Limbah Sapi } \\
\cline { 3 - 9 } No & $\begin{array}{c}\text { Telur } \\
\text { Ayam } \\
\text { Buras }\end{array}$ & Jumlah Telur & $\begin{array}{c}\text { Harga } \\
\text { Satuan } \\
(\text { Rp) }\end{array}$ & $\begin{array}{c}\text { Total Nilai } \\
(\text { Rp) }\end{array}$ & Jumlah Telur & $\begin{array}{c}\text { Harga } \\
\text { Satuan } \\
(\text { Rp) }\end{array}$ & $\begin{array}{c}\text { Total Nilai } \\
\text { (Rp) }\end{array}$ \\
\hline \multirow{2}{*}{1} & $\begin{array}{c}\text { Total } \\
\text { produksi }\end{array}$ & 16.047 & btr & 1.200 & 19.256 .400 & 16.434 & btr & 1.200 & 19.720 .800
\end{tabular}

Sumber: diolah dari data primer 
Berdasarkan Tabel 1,produksi telur yang dihasilkan oleh peternak yang menerapkan teknologi pakan limbah sapi lebih besar dibandingkan peternak yang menerapkan pakan secara konvensional. Penggunaan pakan limbah sapi dalam usaha ternak ayam buras petelur mampu meningkatkan produksi telur. Penerapan teknologi pakan limbah sapi padaayam buras petelur juga memperoleh penerimaan usaha lebih besar dibandingkan penerimaan usaha ayam buras dengan pakan secara konvensional. Artinya, teknologi pakan limbah sapi mampu meningkatkan jumlah penerimaan usaha ayam buras petelur selama harga jual telur tidak berbeda.

\subsubsection{Biayausaha peternakan ayam buras petelur}

Biaya dalam penelitian ini diklasifikasikan ke dalam biaya tetap dan biaya variabel.Biaya variabel yang diperhitungkan adalah biaya input/sarana produksi dan biaya curahan tenaga kerja. Biaya tetap yang diperhitungkan adalah biaya penyusutan alat yang dimiliki untuk usaha ternak ayam buras petelur.Rincian ratarata biaya variabel (variable cost)yang digunakan selain pembuatan kandang disajikan pada tabel 2 .

Tabel 2.

Rata-rata Biaya Sarana Produksi Usaha Peternakan Ayam Buras Petelur Sebanyak 100 Ekor dengan Teknologi Pakan Limbah Sapi dan Menggunakan Pakan Konvensional Selama Satu Siklus Produksi (Mei-Oktober 2014)

\begin{tabular}{|c|c|c|c|c|c|c|c|c|c|}
\hline \multirow{3}{*}{$\begin{array}{l}\text { No } \\
\\
1\end{array}$} & \multirow{3}{*}{$\begin{array}{l}\text { Jenis Input Variabel } \\
\begin{array}{l}\text { Induk ayam buras } \\
\text { petelur }\end{array}\end{array}$} & \multicolumn{4}{|c|}{ Pakan Konvesional } & \multicolumn{4}{|c|}{ Pakan Limbah Sapi } \\
\hline & & \multicolumn{2}{|c|}{$\begin{array}{l}\text { Jumlah } \\
\text { Satuan }\end{array}$} & \multirow{2}{*}{$\begin{array}{c}\text { Harga } \\
\text { Satuan } \\
(\mathrm{Rp})\end{array}$} & \multirow{2}{*}{$\begin{array}{l}\text { Total Nilai } \\
\text { (Rp) } \\
6.000 .000\end{array}$} & \multicolumn{2}{|c|}{$\begin{array}{l}\text { Jumlah } \\
\text { Satuan }\end{array}$} & \multirow{2}{*}{$\begin{array}{c}\text { Harga } \\
\text { Satuan } \\
(\mathrm{Rp})\end{array}$} & \multirow{2}{*}{$\begin{array}{l}\text { Total Nilai } \\
\text { (Rp) } \\
6.000 .000\end{array}$} \\
\hline & & 100 & ek & & & 100 & ek & & \\
\hline 2 & Dedak & 504 & $\mathrm{~kg}$ & 3.000 & 1.512 .000 & 422 & $\mathrm{~kg}$ & 3.000 & 1.266 .000 \\
\hline 3 & Jagung & 576 & $\mathrm{~kg}$ & 3.800 & 2.188 .800 & 603 & $\mathrm{~kg}$ & 3.800 & 2.291 .400 \\
\hline 4 & Konsentrat & 360 & $\mathrm{~kg}$ & 7.300 & 2.628 .000 & 377 & $\mathrm{~kg}$ & 7.300 & 2.752 .100 \\
\hline 5 & $\begin{array}{l}\text { Konsentrat limbah } \\
\text { ternak sapi }\end{array}$ & - & $\mathrm{kg}$ & 1.750 & - & 106 & $\mathrm{~kg}$ & 1.750 & 185.500 \\
\hline 6 & $\begin{array}{l}\text { Vaksin ND (New } \\
\text { castle Deasease) }\end{array}$ & 100 & ek & 500 & 50.000 & 100 & ek & 500 & 50.000 \\
\hline 7 & $\begin{array}{l}\text { Vaksin AI (Avian } \\
\text { Influenza) }\end{array}$ & 100 & ek & 280 & 28.000 & 100 & ek & 280 & 28.000 \\
\hline \multirow[t]{2}{*}{8} & $\begin{array}{l}\text { Tray (keranjang } \\
\text { telur) }\end{array}$ & 535 & bh & 500 & 267.500 & 548 & bh & 500 & 274.000 \\
\hline & $\begin{array}{l}\text { Total Biaya Input } \\
\text { Variabel }\end{array}$ & & & & 12.674 .300 & & & & 12.847 .000 \\
\hline
\end{tabular}

Sumber: diolah dari data primer

Berdasarkan Tabel 2, total biaya sarana produksi yang dikeluarkan petani dalam satu kali siklus produksi sebesar Rp. 12.674.300,00 untuk pakan konvensional dan sebesar Rp. 12.847.000,00 pada ayam dengan teknologi pakan limbah ternak 
sapi.Besarnya biaya input produksi pada kelompok peternak ayam buras petelur dengan menerapkan teknologi pakan limbah sapi disebabkan karena adanya penambahan input konsentrat limbah sapi.Artinya, penambahan pakan limbah sapi untuk ternak ayam buras petelur dapat meningkatkan biaya produksi.

Tabel 3.

Biaya Tenaga Kerja Usaha Peternakan Ayam Buras Petelur Sebanyak 100 Ekor dengan Menggunakan Pakan Konvensional dan Teknologi Pakan Limbah Sapi Selama Satu Siklus Produksi (Mei-Oktober 2014)

\begin{tabular}{|c|c|c|c|c|c|c|c|c|c|c|c|}
\hline \multirow{3}{*}{$\begin{array}{l}\mathrm{N} \\
\mathrm{o}\end{array}$} & \multirow{3}{*}{$\begin{array}{l}\text { Jenis } \\
\text { Tenaga } \\
\text { Kerja }\end{array}$} & \multicolumn{5}{|c|}{ Pakan Konvesional } & \multicolumn{5}{|c|}{ Pakan Limbah Sapi } \\
\hline & & \multirow{2}{*}{$\begin{array}{c}\begin{array}{c}\text { Biaya } \\
\text { TK Luar } \\
\text { Keluarga } \\
(\mathrm{Rp})\end{array} \\
\mathrm{L}\end{array}$} & \multicolumn{3}{|c|}{$\begin{array}{l}\text { Biaya Tenaga Kerja } \\
\text { Keluarga } \\
(\mathrm{Rp})\end{array}$} & \multirow[t]{2}{*}{$\begin{array}{l}\text { Total } \\
\text { Biaya TK } \\
\text { (Rp) }\end{array}$} & \multicolumn{2}{|c|}{$\begin{array}{l}\text { Biaya TK } \\
\text { Luar } \\
\text { Keluarga } \\
\text { (Rp) }\end{array}$} & \multicolumn{2}{|c|}{$\begin{array}{c}\text { Biaya Tenaga Kerja } \\
\text { Keluarga } \\
(\mathrm{Rp})\end{array}$} & \multirow[t]{2}{*}{$\begin{array}{l}\text { Total } \\
\text { Biaya TK } \\
\text { (Rp) }\end{array}$} \\
\hline & & & $\mathrm{P}$ & $\mathrm{L}$ & $\mathrm{P}$ & & $\mathrm{L}$ & $\mathrm{P}$ & $\mathrm{L}$ & $\mathrm{P}$ & \\
\hline 1. & $\begin{array}{l}\text { Pemberian } \\
\text { pakan }\end{array}$ & - & - & 441.000 & 411.600 & 852.600 & - & - & 399.500 & 292.800 & 692.300 \\
\hline 2. & $\begin{array}{l}\text { Pemberian } \\
\text { minum }\end{array}$ & - & - & 441.000 & 411.600 & 852.600 & - & - & 399.500 & 292.800 & 692.300 \\
\hline 3. & $\begin{array}{l}\text { Membersih } \\
\text { kan } \\
\text { kandang }\end{array}$ & - & - & 441.000 & 588.400 & 1.029 .400 & - & - & 632.500 & 399.600 & 1.032 .100 \\
\hline 4. & $\begin{array}{l}\text { Memanen } \\
\text { telur ayam }\end{array}$ & - & - & 294.000 & 764.800 & 1.058 .800 & - & - & 566.000 & 532.400 & 1.098 .400 \\
\hline 5. & Vaksinasi & 200.000 & - & - & - & 200.000 & 200.000 & - & - & - & 200.000 \\
\hline & $\begin{array}{l}\text { Total } \\
\text { Tenaga } \\
\text { Kerja }\end{array}$ & 200.000 & - & 1.617 .000 & 2.176 .400 & 3.993.400 & 200.000 & - & 1.997 .500 & 1.517 .600 & 3.715.100 \\
\hline
\end{tabular}

Sumber: diolah dari data primer

Berdasarkan Tabel 3, peternak ayam buras petelur sebanyak 100 ekor dengan menerapkan pakan secara konvensional membutuhkan curahan tenaga kerja yang lebih banyak dibandingkan dengan penerapan pakan limbah sapi. Penggunaan curahan tenaga kerja sebenarnya hampir sama yang dibutuhkan terhadap satu kandang ayam buras petelur. Hanya saja rata-rata penguasaan ayam buras petelur secara konvensional lebih rendah dibandingkan rata-rata penguasaan ayam buras petelur secara teknologi.

Rata-rata biaya penyusutan alat-alat peternakan untuk usahatani peternakan ayam buras petelur dengan menggunakan pakan konvensional adalah sebesar Rp 686.852,20. Kelompok yang menerapkan teknologi pakan limbah ternak sapi memiliki rata-rata penyusutan alat-alat peternakan sebesar Rp. 518.588,22. Besarnya biaya penyusutan alat disebabkan karena besarnya penyusutan kandang ayam.

\subsubsection{Pendapatan}

Pendapatan usaha ternak ayam buras petelur dengan kapasitas 100 ekor dan menerapkan teknologi pemberian pakan limbah ternak sapi lebih besar dibandingkan pendapatan usaha ternak ayam buras petelur dengan pemberian pakan secara 
konvensional. Besarnya pendapatan usaha ternak ayam buras petelur dengan teknologi pakan limbah sapi disebabkan karena produksi telur yang dihasilkan lebih besar daripada produksi telur dengan pemberian pakan secara konvensional, disajikan pada tabel 4.

\section{Tabel 4.}

Analisis Usaha Peternakan Ayam Buras PetelurSebanyak 100 Ekor di Kelompok Tani Ternak Sato Nadi pada Bulan Mei-Oktober 2014

\begin{tabular}{|c|c|c|c|}
\hline \multirow[t]{3}{*}{ No. } & \multirow[t]{3}{*}{ Keterangan } & \multirow{2}{*}{\multicolumn{2}{|c|}{$\frac{\text { Jenis Teknologi }}{\text { Jumlah (Rp) }}$}} \\
\hline & & & \\
\hline & & Konvensional & Pakan Limbah \\
\hline \multirow[t]{2}{*}{1.} & Penerimaan tunai & & \\
\hline & Total penerimaan dari penjualan telur & 19.256 .400 & 19.720 .800 \\
\hline \multirow[t]{21}{*}{2.} & Biaya tunai & & \\
\hline & a. Biaya variabel & & \\
\hline & $>$ Pembelian bibit & 6.000 .000 & 6.000 .000 \\
\hline & $>$ Pembelian pakan & & \\
\hline & - Dedak & 1.512 .000 & 1.266 .000 \\
\hline & - Jagung & 2.188 .800 & 2.291 .400 \\
\hline & - Konsentrat & 2.628 .000 & 2.752 .100 \\
\hline & - Tepung limbah sapi & - & 185.500 \\
\hline & $>$ Obat-obatan & & \\
\hline & - Vaksin ND (New castle Deasease) & 50.000 & 50.000 \\
\hline & - Vaksin AI (Avian Influenza) & 28.000 & 28.000 \\
\hline & $>$ Tray (keranjang telur) & 267.500 & 274.000 \\
\hline & $>$ Biaya tenaga kerja & 3.993 .400 & 3.715 .100 \\
\hline & Total biaya variabel & 16.667 .700 & 16.562 .100 \\
\hline & b. Biaya tetap & & \\
\hline & - Kandang ayam & $448.972,92$ & $303.313,61$ \\
\hline & - Hand sprayer & $45.751,63$ & $58.100,00$ \\
\hline & - Tempat pakan & $114.117,65$ & $81.794,62$ \\
\hline & - $\quad$ Tempat minum & 69.510 & 65.030 \\
\hline & - Ember & 8.500 & 10.350 \\
\hline & Total biaya tetap & $686.852,20$ & $518.588,22$ \\
\hline 3. & Biaya Total & $17.354 .552,20$ & $17.080 .688,22$ \\
\hline 4. & Total pendapatan usahatani & $1.901 .847,80$ & $2.640 .111,78$ \\
\hline 5. & R/C Ratio & 1,11 & 1,15 \\
\hline
\end{tabular}

Hasil penerimaan, biaya dan pendapatan usaha ternak ayam buras petelur antara kelompok yang menerapkan teknologi pemberian pakan limbah sapi dengan kelompok peternak yang menerapkan pakan secara konvensional, maka akan terlihat berbeda hasilnya jika dilakukan analisis uji beda antara kedua kelompok tersebut. Berdasarkan Tabel 5, perbedaan nilai pendapatan dan kelayakan usaha ternak antara kelompok peternak yang menerapkan teknologi dengan yang menerapkan cara konvensional, memiliki nilai rata-rata yang tidak berbeda nyata. 


\section{Tabel 5.}

Uji Beda Penerimaan, Biaya, Pendapatan dan Kelayakan Usaha Ternak Ayam Buras

Petelur dalam Satu Siklus Pemeliharaan antara Kelompok yang Menerapkan

Teknologi Pakan Limbah Sapi dengan yang Menerapkan Pakan Konvensional di Kelompok Tani Ternak Sato Nadi pada Bulan Mei-Oktober 2014

\begin{tabular}{|c|c|c|c|c|c|c|}
\hline \multirow[b]{2}{*}{ No } & \multirow[b]{2}{*}{ Uraian } & \multicolumn{2}{|c|}{ Rata-rata } & \multirow{2}{*}{\multicolumn{2}{|c|}{ t-hitung }} & \multirow[b]{2}{*}{ t-Tabel } \\
\hline & & $\begin{array}{c}\text { Pakan } \\
\text { Konvensional }\end{array}$ & $\begin{array}{c}\text { Teknologi Pakan } \\
\text { Limbah Sapi }\end{array}$ & & & \\
\hline 1. & Penerimaan (Rp) & $16.368 .000,00$ & $25.637 .538,46$ & 2,410 & $* *$ & $1 \%=2,528$ \\
\hline 2. & Total Biaya (Rp) & $14.612 .526,03$ & $22.074 .838,68$ & 2,225 & $* *$ & $5 \%=1,725$ \\
\hline 3. & Pendapatan (Rp) & $1.755 .473,97$ & $3.562 .699,78$ & 1,129 & $\mathrm{~ns}$ & $10 \%=1,325$ \\
\hline 4. & Kelayakan (R/C) & 1,11 & 1,15 & 0,484 & $\mathrm{~ns}$ & \\
\hline
\end{tabular}

Perbedaan nilai penerimaan dan biaya usaha ternak antara kelompok peternak yang menerapkan teknologi dengan yang menerapkan cara konvensional, memiliki nilai rata-rata yang berbeda nyata. Artinya jika peternak ayam buras petelur menerapkan teknologi pakan limbah sapi, maka peternak akan memperoleh penerimaan yang lebih besar secara nyata dibandingkan dengan cara konvensional karena produksi telur ayam yang diperoleh lebih banyak, begitu juga dengan biaya yang dikeluarkan.

\subsubsection{Kendala-kendala yang dihadapi dalam usaha peternakan ayam buras petelur}

Kendala yang dihadapi dalam usaha peternakan ayam buras petelur adalah sebagai berikut : (1) Faktor peningkatan harga pakan yang tidak diikuti dengan kenaikan harga produksi secara seimbang menyebabkan keuntungan yang diperoleh petani semakin kecil, (2) Pendidikan yang relatif rendah dan usia lanjut mempengaruhi kualitas dan mutu sumber daya manusia (SDM) petani sehingga akan berdampak pada tingkat keterampilan dan penguasaan teknologi, dan(3) Faktor modal memiliki arti yang sangat penting karena akan menentukan kemampuan petani dalam pengembangan usaha peternakannya

\section{Simpulan dan Saran}

\subsection{Simpulan}

1. Rata-rata pendapatan petani dari usaha peternakan ayam buras petelurper 100 ekor dengan menerapkan pakan limbah ternak sapi sebesar Rp.2.640.111,78lebih besar dibandingkan dengan menerapkan pakan secara konvensional sebesar Rp. 1.901.847,80.Perbedaan nilai pendapatan dan kelayakan usaha ternak ayam buras petelur pada kedua kelompok tersebut tidak berbeda nyata. Perbedaan yang nyata terdapat pada penerimaan dan biaya usaha ternak yaitu berbeda pada t-tabeltaraf asebesar 5 persen.Usahapeternakan ayam buras petelur di kelompok tani ternak Sato Nadi 
Desa Jehem yang menerapkan teknologi maupun cara konvensional masingmasing memiliki nilai $\mathrm{R} / \mathrm{C}$ Ratio $\geq 1$, yakni 1,15 dan 1,11.

2. Kendala yang dihadapi dalam usaha peternakan ayam buras petelur di kelompok tani ternak Sato Nadi, Desa Jehem, Kecamatan Tembuku, Kabupaten Bangli antara lain:(a) semakin mahalnya harga pakan yang tidak diikuti dengan kenaikan harga produksi, (b) pendidikan yang relatif rendah dan usia lanjut berpengaruh terhadap kualitas dan mutu sumber daya manusia (SDM) petani, dan (c) adanya keterbatasan modaldalam pengembangan usaha peternakannya.

\subsection{Saran}

Berdasarkan hasil dan pembahasan, maka saran yang dapat disampaikan adalah sebagai berikut :

1. Biaya variabel masih bisa ditekan melalui penggunaan pakan tepung limbah kotoran ternak sapi apabila petani mau mengolah sendiri dan tidak membeli yang siap pakai.

2. Masih perlu adanya penelitian lebih lanjut dan modifikasi mengenai inovasi teknologi pemberian pakan dari limbah ternak sapi agar memberikan perbedaan tingkat pendapatan yang nyata bagi petani ternak ayam buras petelur dibandingkan dengan menggunakan pakan secara konvensional.

\section{Ucapan Terima Kasih}

Pada kesempatan ini penulis menyampaikan rasa terima kasih serta hormat yang sedalam-dalamnya kepada Bapak I Nengah Konci, selaku ketua dan para petani anggota kelompok tani ternak Sato Nadi Desa Jehem, Kecamatan Tembuku, Kabupaten Bangli.

\section{Daftar Pustaka}

BPS. Kab. Bangli. 2015. Bangli dalam Angka. Badan Pusat Statistik Kabupaten Bangli.

Daftar Isian Profil Desa Jehem. 2014. Laporan Data dan Potensi Desa Jehem, Kec. Tembuku - Bangli

Disnak dan Keswan Provinsi Bali. 2013. Informasi Data Peternakan di Provinsi Bali. Dinas Peternakan dan Kesehatan Hewan Provinsi Provinsi Bali Denpasar

Disnak dan Keswan Provinsi Bali. 2014. Laporan Cacah Jiwa Ternak di Provinsi Bali. Dinas Peternakan dan Kesehatan Hewan Provinsi Provinsi Bali Denpasar

Ditjen Peternakan dan Kesehatan Hewan. 2015. Statistik Peternakan dan Kesehatan Hewan. Direktorat Jenderal Peternakan dan Kesehatan Hewan Kementerian Pertanian - Jakarta

Guntoro, S., A.A.N.B Sarmuda Dinata dan Sriyanto. 2014. Laporan Akhir Pemanfaatan Limbah (Kotoran) Sapi untuk Bahan Ransum Ayam Buras. Balai Pengkajian Teknologi Pertanian (BPTP) Bali - Denpasar 
Rasyaf, M. 1992. Pengelolaan Peternakan Unggas Pedaging. Penebar Swadaya, Jakarta.

Rasyaf, M. 1995. Memelihara Ayam Buras. Kanisius, Yogyakarta.

Sinurat, A. P. 1999. Penggunaan Bahan Pakan Lokal dalam Pembuatan Ransum Ayam Buras. Buletin Ilmu Peternakan dan Kesehatan Hewan Indonesia "Wartazoa". Vol 9 No : 1 tahun 2009.

Suwindra, I Nym. 1994. Produktivitas Telur Ayam Buras Bali. Fak. Peternakan UNUD - Denpasar. 